NBER WORKING PAPER SERIES

\title{
ON THE DETERMINANTS OF EXPORTERS' CURRENCY PRICING: HISTORY VS. EXPECTATIONS
}

\author{
Shin-ichi Fukuda \\ Masanori Ono \\ Working Paper 12432 \\ http://www.nber.org/papers/w12432
NATIONAL BUREAU OF ECONOMIC RESEARCH 1050 Massachusetts Avenue
Cambridge, MA 02138
August 2006

\begin{abstract}
An earlier version of this paper was presented at the TRIO conference in Tokyo, the ISR conference in Okinawa, WEAI Conference in San Diego, and the APEF conference in Chuncheon. We would like to thank A. Rose, K. Sato, D. Matsuzaki, A. Belke, S.-J. Baak, an anonymous referee, and other participants of the conference for their helpful comments. Fukuda's research is supported by Japanese Government, Ministry of Education Aid for Science Research on Priority Area \#12124203. The views expressed herein are those of the author(s) and do not necessarily reflect the views of the National Bureau of Economic Research.

(C2006 by Shin-ichi Fukuda and Masanori Ono. All rights reserved. Short sections of text, not to exceed two paragraphs, may be quoted without explicit permission provided that full credit, including $\odot$ notice, is given to the source.
\end{abstract}


On the Determinants of Exporters' Currency Pricing: History vs. Expectations

Shin-ichi Fukuda and Masanori Ono

NBER Working Paper No. 12432

August 2006

JEL No. F12, F31, F33

\begin{abstract}
$\underline{\text { ABSTRACT }}$
The purpose of this paper is to investigate why the choice of invoice currency under exchange rate uncertainty depends not only on expectations but also on history. The analysis is motivated by the fact that the U.S. dollar has historically been the dominant vehicle currency in developing countries. The theoretical analysis is based on an open economy model of monopolistic competition. When the market is competitive enough, the exporting firms tend to set their prices not to deviate from those of the competitors. As a result, a coordination failure can lead the third currency to be a less efficient equilibrium invoice currency. The role of expectations is important in selecting the equilibrium in the static framework. However, in the dynamic model with staggered price-setting, the role of history becomes another key determinant of the equilibrium currency pricing. The role of history may dominate the role of expectations when the firms are myopic, particularly in the competitive local market. It also becomes dominant in the staggered price setting when a small fraction of the new price setters are backward-looking. The result suggests the importance of history in explaining why the firm tends to choose the US dollar as vehicle currency.
\end{abstract}

Shin-ichi Fukuda

Faculty of Economics

University of Tokyo

7-3-1 Hong Bunkyo-ku

Tokyo 113-0033

JAPAN

sfukuda@e.u-tokyo.ac.jp

Masanori Ono

Faculty of Economics and Business Administration

Fukushima University

1 Kanayagawa Fukushima-shi

Fukushima 960-1296

JAPAN

e012@ipc.fukushima-u.ac.jp 


\section{Introduction}

The purpose of this paper is to investigate the choice of invoice currency in developing countries. In previous literature, several theoretical studies investigated the choice of invoice currency in international trade. Baron (1976) and Giovannini (1988) are their early attempts. The authors such as Bacchetta and van Wincoop (2005), Devereux and Engel (2001), and Devereux, Engel, and Storegaard (2004) use a general equilibrium setup. Recent studies that investigate pricing behavior of international trade with developing countries include Frankel, Parsley and Wei (2005). Most of previous studies analyzed the case where the exporting firm sets prices either in the exporters' currency (producer's currency pricing, $\mathrm{PCP}$ ) or in the importers' currency (local currency pricing, LCP). It is, however, well known that some of international trades are invoiced in a third currency, that is, vehicle currency (vehicle currency pricing, VCP). Over most of the past hundred years, first the pound sterling and then the U.S. dollar have played a special role as vehicle currency in international trade. ${ }^{1}$

Except for primary commodities, the role of vehicle currency is relatively limited in international trade among developed countries (see McKinnon [1979] and Magee and Rao [1980]). ${ }^{2}$ The U.S. dollar, however, has historically been the dominant vehicle currency in international trade with developing countries. Many developing countries have chosen the U.S. dollar as the vehicle currency even when they have the other developed countries as important trade partners. The choice of invoice currency is particularly important in developing countries where efficient forward markets as well as other foreign exchange derivatives are missing to hedge the exchange rate risk.

The following theoretical analysis is based on an open economy model of monopolistic competition. Since the export prices are set in advance, the exporting firms face uncertainty of exchange rates. If necessary, the exporting firm set prices in its own currency or in the currency of the importing country. However, when the market is competitive enough, the exporting firms tend to set prices not to deviate from those of the competitors. As a result, when the other exporters are expected to set their prices in the third currency, the exporting firms tends to invoice in the third currency. The tendency becomes conspicuous in the staggered price-setting framework where history becomes a key determinant of the invoice currency.

${ }^{1}$ Historians estimate that $60 \%$ to $90 \%$ of the world's trade was invoiced in the pound sterling in the $19^{\text {th }}$ century. See, for example, Broz (1997). The pound sterling retained its dominant position as key currency in the interwar period, although the UK passed from net creditor to net debtor after World War I.

${ }^{2}$ There are numerous empirical studies that explore the choice of invoice currency. Some of recent studies include Donnenfeld and Haug (2003) for Canadian experience, Fukuda and Ono (2005) for 
Our model follows a partial equilibrium model in Bacchetta and van Wincoop (2002). It, however, has three distinctive features that the previous study did not have. First, we allow the exporting firms to choose the third currency as an invoice currency. In developing countries, the exporting firms are under competition because of less differentiated products. It is thus a natural choice for the exporting firm to set prices in the third currency when the competitors are expected to set their prices in the third currency. The result explains the role of the US dollar as vehicle currency that prevails in many developing countries. Second, we consider a dynamic Nash equilibrium where players move sequentially. The model is in the tradition of Taylor $(1980,2000)$, in that price-setting is staggered. ${ }^{3}$ Firms that adjust their price in a given period set their price to maximize the present discounted value of profits over the periods that the price will be charged. Even in the dynamic Nash equilibrium, the expectations determine the equilibrium currency pricing when the discount rate is negligible.

However, history becomes the key determinant of the equilibrium currency pricing when future profits are discounted, particularly in the competitive local market. Third, we show that a coordination failure can lead the third currency to be an equilibrium invoice currency. Since multiple equilibria are Pareto ranked, it implies that the equilibrium choice of the invoice currency may lead to a less efficient equilibrium. The risk averse exporters are always better off under the exporters' currency pricing than under any other currency pricing. It would be more efficient for the exporters to change their invoice currency from the vehicle currency to their own currency. To improve the welfare, changing their expectations is an important factor. However, when history does matter, it is difficult to change the expectations without reducing the discount rate or increasing their competitiveness.

In previous literature, some studies explored the role of vehicle currency in international trade. Krugman (1980) and Rey (2001) show that transaction costs might make vehicle currency a dominant medium of exchange in international trade. These studies are, however, successful only in explaining the role of vehicle currency as a medium of exchange, through which transactions between currencies are made. In contrast, our approach tries to explain the role of vehicle currency as a unit account in terms of which prices of commodities are set. A unit account is another important function of vehicle currency. Friberg (1998) and Goldberg and Tille (2005) are two exceptional studies that investigated the role of vehicle currency as a unit account. Assuming that the exporter commits to sell the demanded quantity at the ex post realized price, they explored under what conditions the monopolistically competitive exporter chooses the third currency as vehicle currency. None of these studies, however, explored the case where a coordination failure can lead to less efficient equilibrium under vehicle currency pricing. More importantly, these studies are static analysis that could not analyze the case where "history" does matter. It is well known that the U.S. dollar has historically

Korean experience, Fukuda and Ji (1994), Oi, Otani, and Shirota (2004) for Japanese experience, and Wilander (2004) for Swedish experience.

${ }^{3}$ For recent contribution, see Chari, Kehoe, and McGrattan (2000). 
been the dominant vehicle currency in most of developing countries. The following model will show that "history" is a key determinant for the exporters' pricing behavior in developing countries.

The paper proceeds as follows. After providing some empirical evidence on the invoice currency in section 2, section 3 describes our basic model structure. Section 4 drives its Nash equilibria in the static framework. Section 5 explores the dynamic model with the staggered price setting and shows that history does matter on the choice of invoice currency. Section 6 extends the model to the case where some of the new price setters change the expectations as leaders. Section 7 summarizes our results and refers to their implications.

\section{Some Empirical Evidence}

During the past decades, the U.S. dollar has been the dominant vehicle currency in international trade with developing countries. The Bank of Thailand reports various data sets that support this view. Table 1 shows in which currencies Thai exports have been invoiced since 1993. It states that nearly $90 \%$ of Thai exports have been invoiced in the US dollar and that only $10 \%$ have been invoiced in the Japanese yen. The percentages are almost stable throughout the period, although the ratios of the U.S. dollar show marginal declines after 1998.

The view is more strongly supported by Table 2 that reports the invoiced ratios of Thai exports classified by major trade partners. The table indicates that the U.S. dollar tends to be the dominant vehicle currency in Thai exports to various countries. When the United States, Canada, or Mexico are trade partners, almost all of the exports are invoiced in the US dollar. Even when Japan, Europe, or the other East Asian countries are trade partners, majority of the exports are invoiced in the US dollar. For example, in the exports to Japan, more than $70 \%$ are invoiced in the US dollar and only $20 \%$ are invoiced in the Japanese yen. The invoiced ratio in the U.S. dollar is relatively modest in the exports to Germany. However, most of exports are invoiced in the US dollar in the exports to the other European countries, particularly to Denmark, France, Ireland, United Kingdom, and Finland. The dominance of the US dollar also prevails in the exports to other East Asian countries. ${ }^{4}$ In particular, in the exports to Singapore, Malaysia, and Vietnam, more than $90 \%$ are invoiced in the US dollar. Except for the exports to the United States, the US dollar is a third currency in the Thai exports. This implies that the U.S. dollar tends to be chosen as the dominant vehicle currency in invoicing most of Thai exports.

\footnotetext{
4 Exceptions are the exports to Cambodia, Laos, and Myanmar. In the exports, Thai Baht is equally important invoice currency. This is probably because the Thai economy has a strong influence to these countries.
} 
The result is essentially the same for the invoiced currency ratios in Korean exports. Table 3 reports in which currencies Korean exports have been invoiced since 1976. It shows that the invoiced ratios of the US dollar were over $90 \%$ in visible exports and over $80 \%$ in invisible exports. The dominant ratios of the US dollar declined during a past decade years. However, even in recent years, the ratios of the US dollar still lied between $85 \%$ and $90 \%$ in Korean visible exports and around $75 \%$ in Korean invisible trades.

Table 4 summarizes the amount shares of various export destinations from Korea and Thailand. We can see that Japan and Western Europe as well as other Asian countries have been the other important trade partners for Thai and Korean exports. The evidence indicates that the U.S. dollar was chosen as the dominant vehicle currency even in the case where the United States is not a dominant trade partner. It is noteworthy that Japan has been the second biggest partner for both Thai exports and Korean exports. This implies that Thai and Korean exporters choose the U.S. dollar as the vehicle currency even in the exports to one of the most important trade partners.

One may argue that these countries choose the U.S. dollar as the dominant invoice currency because their exchange rates are stable against the U.S. dollar. The argument may have been relevant before the Asian crisis when they effectively pegged their currencies to the U.S. dollar (see, for example, Frankel and Wei [1994]). However, after the crisis, these countries shifted the exchange rate regime from de facto dollar peg to float. As a result, there is no longer a natural reason for them to choose the U.S. dollar as the dominant invoice currency to stabilize their export prices in terms of domestic currencies.

One may also argue that the U.S. dollar is the dominant invoice currency because trading companies are in charge of both exports and imports at the same time. When the amount of exports is equal to the amount of imports, the exchange rate risk can be perfectly diversified. Therefore, if trading companies invoice both exports and imports in the US dollar, they would make a partial diversification of exchange rate risk. Table 5 reports components of Thai export receipts in 2001 and 2002. It shows that about $30 \%$ of export receipts are deposited to foreign currencies in both years. The percentages indicate that Thai exporters may keep some of their foreign exchange receipts for reducing exchange risk in future import payments. The table, however, also reports that about $65 \%$ of export receipts are exchanged from foreign currencies to Thai Baht directly. This implies that more than two thirds of export receipts are still exposed to exchange risk in Thailand.

\section{A Model of Export Pricing Behavior under Exchange Rate Uncertainty}


The purpose of the following sections is to present our theoretical framework that discusses pricing behavior under exchange rate uncertainty. The pricing behavior we study in the following analysis is that of exporters who produce only in their home country. For simplicity, we assume that all exporting firms sell all of their products in a single foreign market. There are three countries: an exporting country, an importing country, and a third country. The third country has no international trade with the other two countries. ${ }^{5}$

Each exporter sets its export price before the exchange rates are known. In setting the export price, it has the choice among its own currency pricing (i.e., producer's currency pricing, PCP), the importers' currency pricing (i.e., local currency pricing, LCP), and the third currency pricing (i.e., vehicle currency pricing, $\mathrm{VCP}$ ). The exchange rates $s_{0}, s$, and $s / s_{0}$ are exogenous and are assumed to be the only source of uncertainty. Selling $s_{0}$ units of the third currency leads to one unit of the importers' currency on the spot market and selling $s$ units of the exporters' currency leads to one unit of the importers' currency on the spot market. By definition, the exchange rate between the exporters' currency and the third currency is given by the relation $s / s_{0}$. For simplicity, we assume that each exchange rate is independently identically distributed with constant mean over time. We also assume that $s$ is uncorrelated with $s_{0}$, so that $E(s-E s)\left(s_{0}-E s_{0}\right)=0$.

In the following analysis, each exporter is under monopolistic competition and firm $j$ faces the demand function $D\left(p_{\mathrm{j}}, P^{*}\right)$, where $p_{\mathrm{j}}$ is the price set by the firm $j$ measured in the importers' currency. $P^{*}$ is the aggregate price index in the importers' local market denominated in the importers' currency. The aggregate price index $P^{*}$ depends on the exchange rate unless all exporting firms set their prices in the importers' currency. We assume that the total number of firms is large enough so that an individual firm does not affect the price index $P^{*}$.

The objective of each exporter is to maximize the expected profits in terms of his (or her) home currency. The central assumptions are that the exporter has to set price before the exchange rates are known and that demand is a function of the price that importers face after exchange rate uncertainty is resolved. Suppose that each exporter chooses $p^{\mathrm{E}}$ under the exporters' currency pricing, $p^{\mathrm{I}}$ under the importers' currency pricing, and $p^{0}$ under the third currency pricing. By definition, the unit price of imports in terms of the importers' currency is $p^{\mathrm{E}} / s$ when invoiced in the exporters' currency, $p^{\mathrm{I}}$ when invoiced in the importers' currency, and $p^{0} / s_{0}$ when invoiced in the third currency. Let $\Pi^{E}, \Pi^{\prime}$, and $\Pi^{\rho}$ denote the exporter's profit under the exporters' currency pricing, under the importers' currency pricing, and under the third currency pricing respectively. The profit from each currency pricing is then respectively given by

\footnotetext{
${ }^{5}$ It would be more natural to suppose that the third country also trades with the two countries. It may make the third currency pricing more likely outcome. The main objective of the following analysis is, however, to show that the third currency might be chosen as an equilibrium invoice currency under a less favorable environment for the third currency pricing.
} 
(1) $\Pi^{E}=p^{\mathrm{E}} D\left(p^{\mathrm{E}} / s, P^{*}\right)-C\left[D\left(p^{\mathrm{E}} / s, P^{*}\right)\right]$,

(2) $\Pi^{H}=s p^{\mathrm{I}} D\left(p^{\mathrm{I}}, P^{*}\right)-C\left[D\left(p^{\mathrm{I}}, P^{*}\right)\right]$,

(3) $\Pi=\left(s / s_{0}\right) p^{0} D\left(p^{0} / s_{0}, P^{*}\right)-C\left[D\left(p^{0} / s_{0}, P^{*}\right)\right]$,

where $C[\cdot]$ is cost function that is strictly increasing and strictly convex. The costs are assumed to be incurred in terms of the exporters' currency.

In the following analysis, we assume that the firms are risk averse and maximize the expected utility from the profits. The utility function of each firm is $U(\Pi)$, which is strictly increasing and strictly concave in $\Pi$.

4. The Static Analysis

(i) The model structure

We first consider the static case where the price is fixed only for a period. In equilibrium, each exporter chooses the exporters' currency pricing if $E U\left(\Pi^{E}\right) \geq E U\left(\Pi^{t}\right)$ and $E U\left(\Pi^{E}\right) \geq E U\left(\Pi^{\circ}\right)$, the importers' currency pricing if $E U\left(\Pi^{t}\right) \geq E U\left(\Pi^{E}\right)$ and $E U\left(\Pi^{f}\right) \geq E U\left(\Pi^{o}\right)$, and the third currency pricing if $E U\left(\Pi^{\uparrow}\right) \geq E U\left(\Pi^{t}\right)$ and $E U\left(\Pi^{\circ}\right) \geq E U\left(\Pi^{E}\right)$. For analytical simplicity, we assume the following set of constant elasticity demand and cost functions:

(4) $D\left(p_{\mathrm{j}}, P^{*}\right)=A\left(p_{\mathrm{j}} / P^{*}\right)^{-\mu}$,

(5) $C(D)=B D^{\eta}$,

where $\mu>1$ and $\eta>1$. If the consumers in the importing country have CES preferences with elasticity $\mu>1$ among the different products, we can specify the demand for goods from firm $j$ as (4). Larger $\mu$ implies higher (smaller) degree of substitutability among the products. The aggregate price index in the importers' local market $P^{*}$ is given by

(6) $P^{*}=\left(\frac{1}{N} \sum_{i=1}^{N} p_{i}^{1-\mu}\right)^{1 /(1-\mu)}$

where $N$ is the number of firms in the importers' local market and $p_{\mathrm{i}}$ is a price set by exporting firm $i$ in the importers' currency. 
Under (4) and (5), the representative exporter's expected utility for each currency denomination is respectively written as

(7) $\left.\left.E U\left(\Pi^{E}\right)=E U\left\{A p^{\mathrm{E}}\left[\left(p^{\mathrm{E}} / s\right) / P^{*}\right)\right]^{-\mu}-A^{\eta} B\left[\left(p^{\mathrm{E}} / s\right) / P^{*}\right)\right]^{-\mu \eta}\right\}$,

(8) $E U\left(\Pi^{\mathrm{I}}\right)=E U\left\{A s p^{\mathrm{I}}\left(p^{\mathrm{I}} / P^{*}\right)^{-\mu}-A^{\eta} B\left(p^{\mathrm{I}} / P^{*}\right)^{-\mu \eta}\right\}$,

(9) $\left.\left.E U\left(\Pi^{\oplus}\right)=E U\left\{A\left(s / s_{0}\right) p^{0}\left[\left(p^{0} / s_{0}\right) / P^{*}\right)\right]^{-\mu}-A^{\eta} B\left[\left(p^{0} / s_{0}\right) / P^{*}\right)\right]^{-\mu \eta}\right\}$.

Since the choice of currency pricing is irrelevant under certainty, it holds that $\Pi^{E}=\Pi^{t}=\Pi^{0} \equiv \Pi^{*}$ near $s_{0}=E s_{0}$ and $s=E s$. We can also show that $p^{\mathrm{E}}=p^{\mathrm{I}} E s=p^{0}\left(E s / E s_{0}\right)=A^{\eta-1} B \mu \eta /(\mu-1)$. It is easy to see that the optimal price is a constant markup $\mu /(\mu-1)$ over the marginal cost $B$.

By using the envelop theorem, a second order Taylor expansion near $s_{0}=E s_{0}$ and $s=E s$ leads to

(10) $E U(\Pi \dot{)}) \approx U\left(\Pi^{*}\right)+(1 / 2) U^{\prime}\left(\Pi^{*}\right)\left(\Pi_{11}^{j} \sigma_{0}^{2}+\Pi_{22}{ }^{2} \sigma^{2}\right)$, for $j=E, I$, and 0 ,

where $\Pi_{11}{ }^{j} \equiv d^{2} \Pi \dot{\Pi} / d s_{0}{ }^{2}$ and $\Pi_{22}{ }^{j} \equiv d^{2} \Pi / d s^{2}$ at $s_{0}=E s_{0}$ and $s=E s$. After some tedious calculations shown in Appendix, we therefore obtain that near $s_{0}=E s_{0}$ and $s=E s$,

(11) $\left[E U\left(\Pi^{\dagger}\right)-E U\left(\Pi^{\prime}\right)\right] / U^{\prime}\left(\Pi^{*}\right)=(1 / 2)\left[\partial^{2} \Pi^{\rho} / \partial s_{0}^{2}+2\left(\partial^{2} \Pi^{\rho} / \partial P^{*} \partial s_{0}\right)\left(\partial P^{* / \partial} s_{0}\right)\right] \sigma_{0}^{2}$, $=-\left\{(1 / 2)\left(1 / s_{0}\right)^{2}[\mu(\eta-1)+1]+\left(1 / p_{0}\right)(\eta-1) \mu\left(\partial P^{*} / \partial s_{0}\right)\right\} p^{\mathrm{E}} A(\mu-1) \sigma_{0}^{2}$,

(12) $\left[E U\left(\Pi^{\uparrow}\right)-E U\left(\Pi^{E}\right)\right] / U^{\prime}\left(\Pi^{*}\right)=(1 / 2)\left\{\left[\partial^{2} \Pi^{\prime} / \partial s_{0}{ }^{2}+2\left(\partial^{2} \Pi^{\oplus} / \partial P^{*} \partial s_{0}\right)\left(\partial P^{*} / \partial s_{0}\right)\right] \sigma_{0}^{2}\right.$

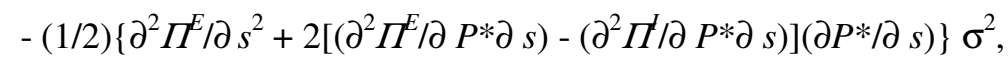$$
=-\left\{(1 / 2)\left(1 / s_{0}\right)^{2}[\mu(\eta-1)+1]+\left(1 / p_{0}\right)(\eta-1) \mu\left(\partial P^{*} / \partial s_{0}\right)\right\} p^{\mathrm{E}} A(\mu-1) \sigma_{0}^{2}
$$$$
+\left\{(1 / 2)(1 / s)^{2} p^{\mathrm{E}}[\mu(\eta-1)-1]+(\eta-1) \mu\left(\partial P^{*} / \partial s\right)\right\} A(\mu-1) \sigma^{2},
$$

(13) $\left[E U\left(\Pi^{\prime}\right)-E U\left(\Pi^{E}\right)\right] / U^{\prime}\left(\Pi^{*}\right)$

$$
=-(1 / 2)\left\{\partial^{2} \Pi^{E} / \partial s^{2}+2\left[\left(\partial^{2} \Pi^{E} / \partial P^{*} \partial s\right)-\left(\partial^{2} \Pi^{L} / \partial P^{*} \partial s\right)\right]\left(\partial P^{*} / \partial s\right)\right\} \sigma^{2},
$$$$
=\left\{(1 / 2)(1 / s)^{2} p^{\mathrm{E}}[\mu(\eta-1)-1]+(\eta-1) \mu\left(\partial P^{*} / \partial s\right)\right\} A(\mu-1) \sigma^{2} \text {. }
$$

where we denote the variances as $\sigma^{2} \equiv E(s-E s)^{2}$ and $\sigma_{0}^{2} \equiv E\left(s_{0}-E s_{0}\right)^{2}$ respectively.

(ii) Nash equilibrium

Based on (11)-(13), we investigate which currency the exporters denominate their product in a Nash equilibrium. Focusing on a symmetric equilibrium, we can show that both the importers' currency pricing and the third currency pricing are a Nash equilibrium if equation (11) is positive, that is, if 
(14) $\mu(\eta-1)>1$.

Both the importers' currency pricing and the third currency pricing are a Nash equilibrium under the same condition because there is a herding effect where the exporting firms keep their prices not to deviate from those of the competitors under the competitive market. When the importers' currency pricing is a Nash equilibrium, the aggregate price $P^{*}=p^{\mathrm{I}}$ is independent of exchange rates, so that equation (11) is always negative. Therefore, the importers' currency pricing is a Nash equilibrium only if equation (13) is positive, that is, $\mu(\eta-1)>1$. When the third currency pricing is a Nash equilibrium, it holds that $P^{*}=p^{0} / s_{0}$. Since $\partial P^{*} / \partial s_{0}=-p^{0} / s_{0}^{2}$ when $P^{*}=p^{0} / s_{0}$, equation (12) is always positive if equation (11) is positive. Therefore, the third currency pricing is a Nash equilibrium only if equation (11) is positive, that is, $\mu(\eta-1)>1$.

In contrast, the exporters' currency pricing is a Nash equilibrium under more general environments. When the exporters' currency pricing is a Nash equilibrium, it holds that $P^{*}=p^{\mathrm{E}} / s$. Since $\partial P^{*} / \partial s=$ $-p^{\mathrm{E}} / s^{2}$ when $P^{*}=p^{\mathrm{E}} / s$, both equations (12) and (13) are negative if

(15) $\mu(\eta-1)+1 \geq 0$,

The exporters' currency pricing is therefore a Nash equilibrium if (15) holds. The exporters' currency pricing is the only Nash equilibrium if $\mu(\eta-1)<1$. The denomination in the exporters' currency tends to be the only Nash equilibrium when the local market is less competitive. However, it is noteworthy that the model has multiple Nash equilibria where any currency pricing is an equilibrium if (14) holds. Under the multiple Nash equilibria, the choice of the currency denomination becomes arbitrary depending on the exporters' expectations on which currency the other exporters will choose (that is, sunspots do matter).

In our model, the multiple Nash equilibria occur when $\mu$ is large, that is, when the market is competitive. In the competitive market, the exporter looses its market shares when its price exceeds the competitors'. It is therefore important for the exporting firms to choose the same currency pricing as that of the competitors. This indicates that the exporters' expectations lead to arbitrary price setting, especially when the exporters face a competitive local market.

It is worthwhile to note that multiple equilibria are Pareto ranked. This implies that the equilibrium choice of invoice currency may be a less efficient equilibrium. The expected utility of each exporter in the Nash equilibrium is respectively written as

(16a) $E U\left(\Pi^{\mathrm{L}}\right)=E U\left(A s p^{\mathrm{I}}-A^{\mathrm{\eta}} B\right)$ under the importers' currency pricing,

(16b) $E U\left(\Pi^{\uparrow}\right)=E U\left[A\left(s / s_{0}\right) p^{0}-A^{\eta} B\right]$ under the third currency pricing, 
(16c) $E U\left(\Pi^{E}\right)=E U\left(A p^{\mathrm{E}}-A^{\mathrm{\eta}} B\right)$ under the exporters' currency pricing.

Since $U\left(\Pi^{E}\right)=U\left(\Pi^{t}\right)=U\left(\Pi^{\prime}\right) \equiv U\left(\Pi^{*}\right)$ near $s_{0}=E s_{0}$ and $s=E s$, equations (16a) - (16c) imply that the risk averse exporters are always better off under the exporters' currency pricing than under any other currency pricing. In addition, the exporters' utility is higher (lower) under the importers' currency pricing than the third currency pricing when the variance of $s$ is smaller (larger) than the variance of $s / s_{0}$. In our model, a coordination failure may make the equilibrium choice of invoice currency less efficient. ${ }^{6}$

\section{The Dynamic Analysis}

(i) The model framework

In the last section, we explored the choice of currency pricing in the static framework. The framework is useful when considering under what circumstances expectations determine the choice of invoice currency in competitive local markets. However, since the expectations are not pathdependent, the static framework cannot explain why history is another key factor in determining equilibrium currency pricing. It is widely observed that the US dollar has historically been the dominant invoice currency in many developing countries. We need a theory that explains why history does matter in determining equilibrium currency pricing.

In this section, we consider a dynamic Nash equilibrium where players move sequentially. As in the previous section, each exporter sets price before the exchange rates are known and the demand is a function of the price that importers face after exchange rate uncertainty is resolved. However, the price contract is long-term so that the exporters cannot change the prices for period $H$. The model is in the tradition of Taylor $(1980,2000)$, in that price-setting is staggered: each firm sets its price for $H$ periods. ${ }^{7}$ In each period, a fraction $1 / H$ of firms can choose their new price but a fraction $1-1 / H$ of firms cannot. Firms that adjust their price in a given period set their price to maximize the present discounted value of profits over the $H$ periods that the price will be charged.

Define the present discounted value of profits as $V_{t}^{E} \equiv \sum_{t=1}^{H} \beta^{t-1} E U\left(\Pi_{t}^{E}\right)$ under the exporters' currency pricing, as $V_{t}{ }^{I} \equiv \sum_{t=1}^{H} \beta^{t-1} E U\left(\Pi_{t}^{I}\right)$ under the importers' currency pricing, and as $V_{t}{ }^{0}$

\footnotetext{
${ }^{6}$ Under symmetric Nash equilibrium, all export prices are equalized, so that $D\left(p_{\mathrm{j}}, P^{*}\right)=A\left(p_{\mathrm{j}} / P^{*}\right)^{-\mu}=$ $A$. The welfare of consumers in the importing countries therefore does not depend on the choice of invoice currency.

${ }^{7}$ It has been more common in recent work with sticky-price models to use the Calvo framework, in which firms face an exogenous, constant probability of being able to adjust their price. The following results essentially hold even in the Calvo framework.
} 
$\equiv \sum_{t=1}^{H} \beta^{t-1} E U\left(\Pi_{t}^{0}\right)$ under the third currency pricing respectively, where $\beta$ is a discount factor. Then, in equilibrium, each exporter chooses the exporters' currency pricing if $V_{t}{ }^{E} \geq V_{t}{ }^{I}$ and $V_{t}{ }^{E} \geq V_{t}{ }^{0}$, the importers' currency pricing if $V_{t}{ }^{I} \geq V_{t}{ }^{E}$ and $V_{t}{ }^{I} \geq V_{t}{ }^{0}$, and the third currency pricing if $V_{t}{ }^{0} \geq V_{t}{ }^{I}$ and $V_{t}{ }^{0} \geq V_{t}{ }^{E}$. Unlike the static model, the dynamic model requires the comparison of the present discounted value of profits over $H$ periods.

If all exporters set the prices simultaneously, the dynamic analysis degenerates into the static case discussed in the last section. In this case, to the extent that the condition (14) holds, only expectations matter in determining equilibrium currency pricing even in the dynamic framework. However, if there is heterogeneity in the price settings, the currency the exporters initially chose could continue to be the equilibrium denomination currency as inertia. The staggered price setting is a useful assumption that incorporates heterogeneity in the price settings in the dynamic framework.

When the equilibrium currency pricing is history dependent and is chosen as inertia, the role of expectations disappears in the dynamic Nash equilibrium because changed expectations are not selffulfilling. To see this, suppose that all of the exporters had historically fixed their prices in the third currency until period 0 . Suppose also that at period 1 , the new price setting exporters formed new expectations that all of the new price setters would fix their prices in the exporters' currency after period 1. If the new expectations are self-fulfilling, switching from the third currency pricing to the extorters' currency pricing at period 1 would be a Nash equilibrium. Otherwise, the third currency pricing would remain the Nash equilibrium even after period 1.

When the expectations are self-fulfilling, it is likely to hold that $E U\left(\Pi_{t}{ }^{E}\right)<E U\left(\Pi_{t}{ }^{o}\right)$ for $t<T$ and that $E U\left(\Pi_{t}^{E}\right)>E U\left(\Pi_{t}^{o}\right)$ for $t \geq T$, where $1<T<H$. This is because the third currency pricing is still dominant among the exporters when $t$ is small but the exporters' currency pricing becomes dominant when $t$ is large. To fulfill the expectations that all of the new price setters would fix their prices in the exporters' currency after period 1 , it is thus necessary that

$$
\sum_{t=T}^{H} \beta^{t-1}\left[E U\left(\Pi_{t}^{E}\right)-E U\left(\Pi_{t}^{0}\right)\right] \geq \sum_{t=1}^{T-1} \beta^{t-1}\left[E U\left(\Pi_{t}^{0}\right)-E U\left(\Pi_{t}^{E}\right)\right]
$$

The above condition is a necessary condition for the exporters' currency pricing to be a new Nash equilibrium. If the condition (17) does not hold, the third currency would remain the equilibrium denomination currency as inertia. ${ }^{8}$

\footnotetext{
${ }^{8}$ Strictly speaking, for the third currency to remain the equilibrium currency, we also need that switching from the third currency pricing to the importers' currency pricing at period 1 would not be a Nash equilibrium.
} 


\section{(ii) Calibration}

To understand what makes the condition (17) less likely to hold and under what conditions the third currency remains to be the Nash equilibrium, we specify the utility function and calculate the expected utility of the profit under three alternative currency pricings. We specified the utility function of the exporters as $U(\Pi) \equiv \sqrt{\Pi} / 2$ and calculated the utilities of the exporters for 10,000 random samples of exchange rates, assuming that the changes of the exchange rates follow standard normal distribution with zero mean. ${ }^{9}$ In the calibration, we choose the parameter set such that $\eta=3, A=1$, and $B=10$. We also set that $H=48$. In our model, a fraction of $1 / H$ of all exporters set prices each period for $H$ periods. The period $H$ always corresponds to the period for the prices are sticky (e.g., one year), so that the large value of $H$ implies the large degree of staggering. Altering the interpretation of the time unit, we can vary $H$ to examine its role in affecting equilibrium currency pricing. For example, if the time unit is weekly or semi-weekly, we can set the value of $H$ reasonably large. What is important in the following calibration is that the value of $H$ needs to be large enough for the price setters to be very heterogeneous.

Figures 1-a, 1-b, and 1-c draw the calibrated values of $E U\left(\Pi_{t}^{E}\right), E U\left(\Pi_{t}{ }^{\circ}\right)$, and $E U\left(\Pi_{t}^{I}\right)$ from $t=1$ to $t=H$ for three alternative values of $\mu: \mu=5,7.5$, and 10 . The calibrated values are based on the assumption that all of the exporters had fixed their prices in the third currency until period 0 but that all of the new price setters would fix their prices in the exporters' currency after period 1. Regardless of the choice of $\mu, E U\left(\Pi_{t}^{o}\right)$ exceeds both $E U\left(\Pi_{t}{ }^{E}\right)$ and $E U\left(\Pi_{t}{ }^{I}\right)$ when $t<24$, while $E U\left(\Pi_{t}{ }^{E}\right)$ exceeds both $E U\left(\Pi_{t}{ }^{\circ}\right)$ and $E U\left(\Pi_{t}{ }^{I}\right)$ when $t \geq 24$. This reflects the fact that the third currency pricing is still dominant among the exporters when $t$ is small but the exporters' currency pricing becomes dominant when $t$ is large. Analytically, the overall price index at period $t(t=1,2, \ldots, H)$ is

$$
P_{t}^{*}=\left[\left(\frac{t}{H}\right)\left(p^{E} / s\right)^{1-\mu}+\left(1-\frac{t}{H}\right)\left(p^{0} / s_{0}\right)^{1-\mu}\right]^{1 /(1-\mu)}
$$

Even after period 1 , a fraction $1-\mathrm{t} / H$ of firms still keep denominating the price in the third currency at period $t(t=1,2, \ldots, H)$ in the staggered price setting. The weight of firms that keep denominating the price in the third currency is large when $t$ is small but declines over time. The weight of firms that denominates the price in the exporters' currency becomes large when $t$ is large. The calibrated utilities in the figures reflect these environments.

When the discount factor $\beta$ is small (that is, when the exporters are myopic and discount the future profits enough), the losses from changing expectations always dominate the benefits in the future. It 
is therefore costly to change the denomination currency, so that the exporters' currency pricing will not be a new Nash equilibrium. For example, when $\beta=0.98, V_{t}{ }^{0}=298.69, V_{t}{ }^{E}=298.32$, and $V_{t}^{I}=$ 298.52 when $\mu=10 ; V_{t}^{0}=307.34, V_{t}^{E}=307.18$, and $V_{t}^{I}=307.27$ when $\mu=7.5 ; V_{t}^{0}=325.27, V_{t}^{E}=$ 325.23, and $V_{t}^{I}=325.25$ when $\mu=5$. The condition (17) does not hold for any of the three alternative values of $\mu$. Since the exporters have no incentive to change its denomination currency from the third currency to the exporters' currency, they continue the third currency pricing as inertia when the future profits are discounted enough.

In contrast, when $\beta$ is very close to one, the changed expectations can lead the exporters' currency pricing to be a new Nash equilibrium. When $\beta=1, V_{t}{ }^{0}=461.36, V_{t}{ }^{E}=461.79$, and $V_{t}^{I}=461.60$ when $\mu=10 ; V_{t}{ }^{0}=474.98, V_{t}^{E}=475.27$, and $V_{t}^{I}=475.13$ when $\mu=7.5 ; V_{t}{ }^{0}=502.85, V_{t}^{E}=503.02$, and $V_{t}^{I}=502.94$ when $\mu=5$. In our parameter set, $V_{t}{ }^{E}$ always exceeds both $V_{t}{ }^{0}$ and $V_{t}^{I}$ under the changed expectations for any of the three alternative values of $\mu$. The exporters have an incentive to change its denomination currency from the third currency to the exporters' currency when the exporters do not discount the future profits. Only expectations play the essential role in changing the equilibrium currency pricing. To the extent that all of the new price setters are expected to fix their prices in the exporters' currency after period 1, the exporters' currency pricing always becomes a new Nash equilibrium after period 1 when $\beta=1$. It is, however, worthwhile to note that the exporters need to change the expectations after period 1 for the exporters' currency pricing to be an equilibrium. If none of the new price setters changed the expectations at period 1, the third currency pricing would remain a Nash equilibrium after period 1 even when $\beta=1$.

In our parameter set, some intermediate cases arise when $\beta$ is around 0.99 . When $\beta=0.99, V_{t}{ }^{0}=$ $368.06, V_{t}^{E}=368.00$, and $V_{t}^{I}=368.05$ when $\mu=10 ; V_{t}{ }^{0}=378.82, V_{t}{ }^{E}=378.84$, and $V_{t}^{I}=378.84$ when $\mu=7.5 ; V_{t}^{0}=400.98, V_{t}^{E}=401.02$, and $V_{t}^{I}=401.01$ when $\mu=5$. The exporters have an incentive to change its denomination currency from the third currency to the exporters' currency if $\mu=$ 5 or 7.5 but do not if $\mu=10$. When $\beta=0.9875, V_{t}{ }^{0}=348.77, V_{t}{ }^{E}=348.62$, and $V_{t}^{I}=348.72$ when $\mu$ $=10 ; V_{t}^{0}=358.95, V_{t}^{E}=358.91$, and $V_{t}^{I}=358.94$ when $\mu=7.5 ; V_{t}^{0}=379.93, V_{t}^{E}=379.95$, and $V_{t}^{I}$ $=379.94$ when $\mu=5$. The exporters have an incentive to change its denomination currency from the third currency to the exporters' currency if $\mu=5$ but do not if $\mu=10$ or 7.5 . Note that the parameter $\mu$ becomes large when the importers' local market is competitive. Because of less differentiated products, competitive local market is more relevant for exporters in developing countries. It is therefore more likely that the exporters continue the third currency pricing as inertia in developing countries.

\footnotetext{
${ }^{9}$ In the calibrations, we also tried varieties of normal distributions with different variances. The essential results were, however, the same.
} 
As in the static model, the risk averse exporters are always better off under the exporters' currency pricing than under any other currency pricing in the long-run. Therefore, even in the dynamic Nash equilibrium model, a coordination failure may make the equilibrium currency pricing less efficient. However, unlike in the static model, not only expectations but also history plays a key role in determining the equilibrium currency pricing. The exporters know that moving from the third currency pricing to the exporters' currency pricing is desirable in the long-run. However, they also know that majority of the other exporters cannot change the past currency pricing rule in the short-run. History therefore discourages their incentive to change the currency pricing role. The role of history becomes particularly important when the price settings are very heterogeneous, when the future profits are discounted, and when the local market is competitive.

In most developing countries, the US dollar has historically been the dominant vehicle currency. This has been true even when the other developed countries are another trade partners for the developing countries. Once a country's currency is established as an invoice currency, a large change in economic environment is necessary to replace it, even if the relative economic power of that country has declined in world trade. In the long-run, it would be more efficient for the exporters to change their invoice currency from the vehicle currency to their own currency. To achieve the longrun goal, changing their expectations is an important factor. However, when history does matter, making the firms less myopic and increasing their competitiveness would be the other important factors to improve their welfare.

\section{The Model with Backward-looking Price Setters}

In the last section, we investigated a dynamic Nash equilibrium where all of the new price setters change the expectations simultaneously. However, given that all of the exporters had fixed their prices in the third currency until period 0 , it is less likely that all of the new price setters would suddenly change their expectations on currency pricing after period 1. Instead, it is more likely that some of the new price setters form backward-looking expectations at period 1. Only forward-looking leaders would change the expectations at period 1 and that the other new price setters would follow the leaders after period 2. The purpose of this section is to investigate a dynamic equilibrium under such expectation formation with inertia.

As in the last section, all of the exporters had fixed their prices in the third currency until period 0. However, unlike in the last section, we assume that a fraction $\alpha$ of the new price setters $(0<\alpha<1)$ observed a sunspot at the beginning of period 1. Only those who observed the sunspot fix their prices in the exporters' currency at period 1 and form new expectations that all of the new price setters would follow the currency pricing after period 2. If the new expectations are self-fulfilling, switching from the third currency pricing to the extorters' currency pricing at period 1 would be a new 
equilibrium. Otherwise, the third currency pricing would remain the only equilibrium even after period 1. When the fraction $\alpha$ is large enough, it still holds that $E U\left(\Pi_{t}{ }^{E}\right)<E U\left(\Pi_{t}{ }^{\circ}\right)$ for $t<T^{*}$ and that $E U\left(\Pi_{t}^{E}\right)>E U\left(\Pi_{t}{ }^{\circ}\right)$ for $t \geq T^{*}$, where $1<T^{*}<H$. However, $T^{*}$ becomes larger as $\alpha$ become smaller. This is because a fraction 1- $\alpha$ of the exporters, who had chosen the third currency pricing at period 1, cannot change their currency pricing until period $H+1$.

Like the last section, we specify the utility function of the exporters as $U(\Pi) \equiv \sqrt{\Pi} / 2$ and choose the parameter set such that $\eta=3, \mu=7.5, A=1$, and $B=10$ in the calibration. Unlike the last section, we set that $H=5$ (so that the unit of time is monthly). The use of the lower value of $H$ is to demonstrate whether history matters or not even if the price setters are less heterogeneous. Without backward-looking price setters (that is, when $\alpha=1$ ), the new expectations would be self-fulfilling unless $\beta$ is unreasonably small. However, when $\alpha$ is less than 1 , the new expectations may not be self-fulfilling even if $\beta$ is close to one.

We calculated the utilities of the exporters for 10,000 random samples of exchange rates, assuming that the changes of the exchange rates follow standard normal distribution with zero mean. Table 6 reports the calibrated values of $V_{t}^{E}, V_{t}^{I}$, and $V_{t}{ }^{0}$ for alternative values of $\alpha$ and $\beta$. When $\alpha=1, V_{t}^{E}$ exceeds both $V_{t}{ }^{I}$ and $V_{t}{ }^{0}$ if $\beta$ is greater than 0.71 . When $\alpha=0.9, V_{t}{ }^{E}$ still exceeds both $V_{t}{ }^{I}$ and $V_{t}{ }^{0}$ if $\beta$ is greater than 0.82 . This implies that the expectations are self-fulfilling under reasonable discount factors if most of the new price setters observe the sunspot at the beginning of period 1 . In contrast, when $\alpha=0.75$, neither $V_{t}{ }^{E}$ nor $V_{t}{ }^{I}$ exceeds $V_{t}{ }^{0}$ even if $\beta=1$. This implies that more than three-fourth of the new price setters need to be forward-looking leaders at period 1 for the exporters' currency to be a new equilibrium. Some intermediate case arises when $\alpha$ is equal to 0.8 . The exporters have an incentive to change its denomination currency from the third currency to the exporters' currency if $\beta$ is greater than 0.97 but do not if $\beta$ is less than 0.955 . In the intermediate case, the discount rate plays a critical role on the choice of currency pricing.

When we change the value of $H$ to be 1 (that is, no price staggering), the calibration shows that $V_{t}{ }^{E}$ always exceeds both $V_{t}{ }^{I}$ and $V_{t}{ }^{0}$ if $\alpha \geq 0.47$. Therefore, in the static framework, the exporters' currency can be a new equilibrium even when half of the new price setters are backward-looking. In contrast, the exporters' currency can be a new equilibrium in the dynamic framework with staggered price setting even if much larger fraction of the new price setters are forward-looking. This happens because not only backward-looking price setters but also non-price setters keep the old currency pricing when the prices are staggered. This implies that the role of history becomes dominant in the staggered price setting even when a relatively small fraction of the new price setters are backwardlooking. It is true even if the degree of heterogeneity is not large. 
In practice, firm's pricing (invoicing) contract is at most several months. Therefore, when the value of $H$ is large, we need to set the interpretation of the time unit reasonably short. In particular, when the time unit is reasonably short, a realistic discount factor $\beta$ would be very close to one. The above results thus suggest that the existence of backward-looking price setters will provide more reasonable environments where history plays a key role in determining the equilibrium currency pricing. However, our results also suggest that unless the value of $H$ is very small, a fraction of backwardlooking setters need not be so large.

\section{Concluding Remarks}

This paper investigated the choice of invoice currency under exchange rate uncertainty. The analysis was motivated by the fact that the U.S. dollar has historically been the dominant vehicle currency in developing countries. When the market is competitive enough, the exporting firms tend to set their prices not to deviate from those of the competitors. As a result, when the other exporters are expected to set their prices in a third currency, the exporting firm tends to choose the third currency as an equilibrium invoice currency. In particular, in the staggered price-setting framework, history becomes a key determinant of the equilibrium currency pricing when the firms discount future profits, particularly in the competitive local market, and when there are backward-looking price setters.

For analytical tractability, we used several assumptions in the model. Although the simplified assumptions allowed us to focus an essential aspect on the determinants of currency pricing, our paper may have neglected several other important aspects. For example, we solely focused on the case where exporters have monopoly power but importers do not. The model of monopolistic competition where exporters have monopoly power is standard in literature and may make it easy to compare our results with previous studies. However, importers have monopoly power in some international trades from developing countries to developed countries. If importers have monopoly power, the importers' currency pricing (local currency pricing, LCP) may be more likely to be chosen when the market is less competitive. The extension is our important agenda for our future researches. Our analysis also relied on several specific functional forms. It is worthwhile to note that exchange rate volatilities play no role in determining the equilibrium invoice currency under the specific functional forms. However, exchange rate volatilities can affect the equilibrium choice of invoice currency under more general functional forms. If this is the case, which exchange rate regime the exporters' country adopts might be an important determinant of the invoice currency.

One of the motivations of the paper was based on the fact that the US dollar has been the dominant invoice currency in several East Asian countries. However, the dominant role of the US dollar had also prevailed in Japanese exports until very recently. As Japanese economy showed remarkable 
growth, the role of Japan's exports in international trade increased substantially in the 1960s and the 1970s. The share of the Japanese Yen's denomination in the Japan's exports, however, had been negligible until the early 1970s. Table 7 reports time-series data of invoice currency data in Japan's exports. The Yen's invoice ratios were close to zero in the early 1970s and were less than $20 \%$ throughout the 1970s. It was 1983 when the Yen's share exceeded 40\% in the Japan's exports to the world. But the Yen's invoice ratios were not far above $40 \%$ even in the early 1990s and declined below 40\% throughout the 1990s. The Yen's ratios in the exports were not high even for East Asia, although they were slightly higher than for the rest of the world.

In explaining the determinants of invoice currencies in Japan's exports, we may point out several factors that were not discussed in the paper. The first is the heavy reliance of Japan's exports on the United States. Since only a small fraction (16 percent in 1991) of Japanese exports to the United States are invoiced in the yen and since a large fraction of Japanese exports go to the United States, the structure of Japan's exports leads to relatively low yen-denominated invoice currency ratios in Japan's total exports. The structure may affect the choice of invoice currency on Japan's exports to the other countries. The second is the relatively small size of the short-term capital market in Japan. Although its volume has been increasing recently, the size of the treasury bill market in Japan is still much smaller than in the United States. Since the short-term capital market would be where foreign investors would park their yen-denominated funds, its limited size reduces the invoice currency ratio of the yen in trade. The third is the role of Japan's large trading companies, which handle the bulk of Japanese exports and imports. Since these companies have a relative advantage in avoiding foreign exchange risks, their existence may lead to relatively low yen-denominated invoice currency ratios in Japan's total exports. However, in addition to these factors, it is likely that both history and expectations have been the important factors. Due to the previous economic power, the U.S. dollar still plays an important role in Japan's international trade. The expectations support the inertia.

Although Japan's economic power in world trade has risen, it would be a long way for the yen to be the key currency in world trade. 


\section{References}

Bacchetta, P., and E. van Wincoop, (2005), “A Theory of the Currency Determination of International Trade," Journal of International Economics, 67, pp. 295-319.

Baron, D.P., (1976), "Fluctuating Exchange Rates and the Pricing of Exports," Economic Inquiry 14, pp.425-438.

Broz, L., (1997), The International Origins of the Federal Reserve System, Cornell University Press: Ithaca.

Chari, V.V., P.J. Kehoe, and E.R. McGrattan, (2000), "Sticky Price Models of the Business Cycle: Can the Contract Multiplier Solve the Persistence Problem?," Econometrica, 68, pp. 1151-1179.

Devereux, M., and C. Engel. (2001), "Endogenous Currency of Price Setting in a Dynamic Open Economy Model". NBER working paper no. 8559.

Devereux, M., C. Engel, and P.E. Storegaard, (2004), “Endogenous Exchange Rate Pass-through When Nominal Prices are Set in Advance" Journal of International Economics, 63, pp. 263-291.

Donnenfeld, S., and A. Haug, (2003), "Currency Invoicing in International Trade: An Empirical Investigation" Review of International Economics, Vol. 11, pp. 332-345.

Frankel, J.A., and S.-J. Wei, (1994), "Yen Bloc or Dollar Bloc: Exchange Rate Policies of the East Asian Economies," in T. Ito and A. O. Krueger eds., Macroeconomic Linkage, Chicago:

University of Chicago Press.

Frankel, J., D. Parsley and S.-J. Wei, (2005), "Slow Passthrough Around the World: A New Import for Developing Countries?" NBER Working Papers: 11199.

Friberg, R., (1998), “In Which Currency Should Exporters Set Their Prices?” Journal of International Economics 45, pp.59-76.

Fukuda, S., (1995), "The Structural Determinants of Invoice Currencies in Japan: The Case of Foreign Trades with East Asian Countries" in T. Ito and A. O. Krueger eds., Financial Deregulation and Integration in East Asia, Chicago: University of Chicago Press.

Fukuda, S.,and Ji Cong (1994),"On the Choice of Invoice Currency: The PTM Approach," Journal of the Japanese and International Economies 8, pp.511-529.

Fukuda, S.,and M. Ono, (2005), “The Choice of Invoice Currency under Exchange Rate Uncertainty: Theory and Evidence from Korea," Journal of the Korean Economy, 6, pp.161-193..

Giovannini, A., (1988), “Exchange Rates and Traded Goods Prices,” Journal of International Economics 24, pp.45-68.

Goldberg, L.S., and C. Tille, (2005), "Vehicle Currency Use in International Trade," NBER Working Papers \#11127. 
Ito, T., (1993), "The Yen and the International Monetary System," in C.F. Bergsten and M. Noland eds. Pacific Dynamism and International Monetary System, Institute of International Economics. Kawai, M., (1996), "The Japanese Yen as an International Currency: Performance and Prospects," in R. Sato and H. Hori eds., Organization, Performance, and Equity: Perspectives on the Japanese Economy, Kluwer Academic Publishers, Boston, pp.334-387.

Krugman, P., (1984), "Vehicle Currencies and the Structure of International Exchange," Journal of Money, Credit and Banking 12, pp.503-526.

Krugman, P., (1991), "History versus Expectations," Quarterly Journal of Economics, 106, pp. 651-67. Magee, S.P., and R.K.S. Rao (1980), "Vehicle and Nonvehicle Currencies in International Trade," American Economic Review 70, pp.368-373.

Matsuyama, K., N. Kiyotaki, and A. Matsui, (1993), "Toward a Theory of International Currency," Review of Economic Studies, 60, pp.283-307.

McKinnon, R., (1979), Money in International Exchange: The Convertible Currency System, Oxford: Oxford University Press.

Oi, H., A. Otani, and T. Shirota, (2004), "The Choice of Invoice Currency in International Trade: Implications for the Internationalization of the Yen" Monetary and Economic Studies (March) pp.27-63.

Rey, H., (2001), “International Trade and Currency Exchange,” Review of Economic Studies 68, pp.443-464.

Taylor, J.B., (1980), “Aggregate Dynamics and Staggered Contracts,” Journal of Political Economy, 88, pp. 1-23.

Taylor, J.B., (2000), “Low Inflation, Pass-through, and the Pricing Power of Firms,” European Economic Review, 44, pp. 1389-1408.

Wilander, F., (2004), “An Empirical Analysis of the Currency Denomination in International Trade," working paper, Stockholm School of Economics. 


\section{Appendix: Derivations of (11)-(13).}

Equations (1)-(3) and (6) imply that $\partial \Pi^{E} / \partial P^{*}=\partial \Pi^{t} / \partial P^{*}=\partial \Pi^{\oplus} / \partial P^{*}, \partial^{2} \Pi^{t} / \partial P^{*} \partial s=\partial^{2} \Pi^{f} / \partial P^{*} \partial s$ and $\partial^{2} \Pi^{E} / \partial^{2} P^{*}=\partial^{2} \Pi^{1} / \partial^{2} P^{*}=\partial^{2} \Pi^{\rho} / \partial^{2} P^{*}$ at $s_{0}=E s_{0}$ and $s=E s$. It thus holds that when $\partial P^{*} / \partial s=0$,

(A1) $\Pi_{11}{ }^{E}=\Pi_{11}{ }^{I}=\left(\partial^{2} \Pi^{E} / \partial^{2} P^{*}\right)\left(\partial P^{*} / \partial s_{0}\right)^{2}+\left(\partial \Pi^{E} / \partial P^{*}\right)\left(\partial^{2} P^{*} / \partial^{2} s_{0}\right)$,

(A2) $\Pi_{11}{ }^{0}=\left[\Pi_{11}{ }^{E}+\partial^{2} \Pi \rho / \partial s_{0}{ }^{2}+2\left(\partial^{2} \Pi \rho / \partial P^{*} \partial s_{0}\right)\left(\partial P^{*} / \partial s_{0}\right)\right]\left(\partial P^{*} / \partial s_{0}\right)+\left(\partial^{2} \Pi \rho / \partial s_{0}{ }^{2}\right)\left(\partial P^{*} / \partial s\right)$,

(A3) $\Pi_{22}{ }^{I}=\Pi_{22}{ }^{0}=\left(\partial^{2} \Pi / \partial^{2} P^{*}\right)\left(\partial P^{*} / \partial s\right)^{2}+\left(\partial \Pi^{t} / \partial P^{*}\right)\left(\partial^{2} P^{*} / \partial^{2} s\right)+2\left(\partial^{2} \Pi^{t} / \partial P^{*} \partial s\right)\left(\partial P^{*} / \partial s\right)$,

(A4) $\Pi_{22}{ }^{E}=\left(\partial^{2} \Pi^{E} / \partial s^{2}\right)\left(\partial P^{*} / \partial s_{0}\right)$

$$
+\left[\Pi_{22}{ }^{I}+\partial^{2} \Pi^{E} / \partial s^{2}+2\left[\left(\partial^{2} \Pi^{E} / \partial P^{*} \partial s\right)-\left(\partial^{2} \Pi^{I} / \partial P^{*} \partial s\right)\right]\left(\partial P^{*} / \partial s\right)\right]\left(\partial P^{* / \partial} s\right)
$$

at $s_{0}=E s_{0}$ and $s=E s$.

Since equation (10) lead to

(A5) $\left[E U\left(\Pi^{0}\right)-E U\left(\Pi^{\prime}\right)\right] / U^{\prime}\left(\Pi^{*}\right)=(1 / 2)\left[\left(\Pi_{11}{ }^{0}-\Pi_{11}{ }^{I}\right) \sigma_{0}{ }^{2}+\left(\Pi_{22}{ }^{0}-\Pi_{22}{ }^{I}\right) \sigma^{2}\right]$,

(A6) $\left[E U\left(\Pi^{0}\right)-E U\left(\Pi^{E}\right)\right] / U^{\prime}\left(\Pi^{*}\right)=(1 / 2)\left[\left(\Pi_{11}{ }^{0}-\Pi_{11}{ }^{E}\right) \sigma_{0}{ }^{2}+\left(\Pi_{22}{ }^{0}-\Pi_{22}{ }^{E}\right) \sigma^{2}\right]$,

(A7) $\left[E U\left(\Pi^{\prime}\right)-E U\left(\Pi^{E}\right)\right] / U^{\prime}\left(\Pi^{*}\right)=(1 / 2)\left[\left(\Pi_{11}{ }^{I}-\Pi_{11}{ }^{E}\right) \sigma_{0}{ }^{2}+\left(\Pi_{22}{ }^{I}-\Pi_{22}{ }^{E}\right) \sigma^{2}\right]$,

we can derive that

(A8) $\left[E U\left(\Pi^{\uparrow}\right)-E U\left(\Pi^{\prime}\right)\right] / U^{\prime}\left(\Pi^{*}\right)=(1 / 2)\left(\partial P^{*} / \partial s_{0}\right)\left[\partial^{2} \Pi^{\oplus} / \partial s_{0}{ }^{2}+2\left(\partial^{2} \Pi^{\oplus} / \partial P^{*} \partial s_{0}\right)\left(\partial P^{*} / \partial s_{0}\right)\right] \sigma_{0}^{2}$ $+(1 / 2)\left(\partial P^{*} / \partial s\right)\left(\partial^{2} \Pi^{\oplus} / \partial s_{0}^{2}\right) \sigma_{0}^{2}$,

(A9) $\left[E U\left(\Pi^{\top}\right)-E U\left(\Pi^{E}\right)\right] / U^{\prime}\left(\Pi^{*}\right)=(1 / 2)\left(\partial P^{*} / \partial s_{0}\right)\left\{\left[\partial^{2} \Pi^{9} / \partial s_{0}{ }^{2}+2\left(\partial^{2} \Pi^{9} / \partial P^{*} \partial s_{0}\right)\left(\partial P^{*} / \partial s_{0}\right)\right] \sigma_{0}{ }^{2}\right.$

$\left.-\left(\partial^{2} \Pi^{E} / \partial s^{2}\right) \sigma^{2}\right\}+(1 / 2)\left(\partial P^{*} / \partial s\right)\left(\left(\partial^{2} \Pi^{0} / \partial s_{0}{ }^{2}\right) \sigma_{0}^{2}\right.$

$\left.-\left\{\partial^{2} \Pi^{E} / \partial s^{2}+2\left[\left(\partial^{2} \Pi^{E} / \partial P^{*} \partial s\right)-\left(\partial^{2} \Pi^{l} / \partial P^{*} \partial s\right)\right]\left(\partial P^{*} / \partial s\right)\right\} \sigma^{2}\right)$,

(A10) $\left[E U\left(\Pi^{\prime}\right)-E U\left(\Pi^{E}\right)\right] / U^{\prime}\left(\Pi^{*}\right)=-(1 / 2)\left(\partial P^{*} / \partial s_{0}\right)\left(\partial^{2} \Pi^{E} / \partial s^{2}\right) \sigma^{2}$

- (1/2) $\left(\partial P^{*} / \partial s\right)\left\{\partial^{2} \Pi^{E} / \partial s^{2}+2\left[\left(\partial^{2} \Pi^{E} / \partial P^{*} \partial s\right)-\left(\partial^{2} \Pi^{t} / \partial P^{*} \partial s\right)\right]\left(\partial P^{*} / \partial s\right)\right\} \sigma^{2}$.

Equations (7), (8), and (9) lead to

(A11) $\partial \Pi^{E} / \partial s=A \mu p^{\mathrm{E} 1-\mu} s^{\mu-1} P^{* \mu}-\mu \eta A^{\eta} B s^{\mu \eta-1}\left(P^{*} / p^{\mathrm{E}}\right)^{\mu \eta}$,

(A12) $\partial \Pi^{\mathrm{H}} / \partial s=A p^{\mathrm{I} 1-\mu-} P^{* \mu}$,

(A13) $\partial \Gamma^{\rho} / \partial s_{0}=A(\mu-1) s p^{01-\mu} s_{0}^{\mu-2} P^{* \mu}-\mu \eta A^{\eta} B s_{0}^{\mu \eta-1}\left(P^{*} / p^{0}\right)^{\mu \eta}$, 
Since $P^{*} E s=p^{\mathrm{E}}=p^{\mathrm{I}} E s=p^{0}\left(E s / E s_{0}\right)=A^{\eta-1} B \mu \eta /(\mu-1)$ at $s_{0}=E s_{0}$ and $s=E s$, it holds that

(A14) $\partial^{2} \Pi^{0} / \partial s_{0}^{2}=(\mu-1)(\mu-2) A s p^{0} s_{0}^{-3}\left(P^{*} s_{0} / p^{0}\right)^{\mu}-\mu \eta(\mu \eta-1) A^{\eta} B s_{0}^{-2}\left(P^{*} s_{0} / p^{0}\right)^{\mu \eta}$, $=\left(1 / s_{0}\right)^{2}\left[(\mu-1)(\mu-2) A p^{0}\left(s / s_{0}\right)-\mu \eta A^{\eta} B(\mu \eta-1)\right]$,

$=-\left(1 / s_{0}\right)^{2} p^{\mathrm{E}} A(\mu-1)[\mu(\eta-1)+1]<0$

(A15) $\partial^{2} \Pi^{E} / \partial s^{2}=\mu(\mu-1) A p^{\mathrm{E}} s^{-2}\left(P^{*} s / p^{\mathrm{E}}\right)^{\mu}-\mu \eta A^{\eta} B(\mu \eta-1) s^{-2}\left(P^{*} s / p^{\mathrm{E}}\right)^{\mu \eta}$,

$=(1 / s)^{2}\left[\mu(\mu-1) A p^{\mathrm{E}} s^{-2}-\mu \eta A^{\eta} B(\mu \eta-1)\right]$,

$=-(1 / s)^{2} p^{\mathrm{E}} A(\mu-1)[\mu(\eta-1)-1]$,

(A16) $\partial^{2} \Pi^{\ominus} / \partial P^{*} \partial s_{0}=A \mu(\mu-1)\left(s / s_{0}\right)\left(P^{*} s_{0} / p^{0}\right)^{\mu-1}-(\mu \eta)^{2} A^{\eta} B\left(1 / p^{0}\right)\left(P^{*} s_{0} / p^{0}\right)^{\mu \eta-1}$,

$=\left(1 / p^{0}\right)\left[A \mu(\mu-1)\left(p^{0} s / s_{0}\right)-(\mu \eta)^{2} A^{\eta} B\right]$,

$=-\left(p^{\mathrm{E}} / p_{0}\right) A(\mu-1) \mu(\eta-1)<0$,

(A17) $\partial^{2} \Pi^{E} / \partial P^{*} \partial s=A \mu^{2}\left(P^{*} s / p^{\mathrm{E}}\right)^{\mu-1}-(\mu \eta)^{2} A^{\eta} B\left(1 / p^{\mathrm{E}}\right)\left(P^{*} / s p^{\mathrm{E}}\right)^{\mu \eta-1}$,

$=A \mu^{2}-(\mu \eta)^{2} A^{\eta} B\left(1 / p^{\mathrm{E}}\right)$,

$=-A \mu[\mu(\eta-1)-\eta]$,

(A18) $\partial^{2} \Pi^{\mathrm{L}} / \partial P^{*} \partial s=A \mu\left(P^{*} / p^{\mathrm{I}}\right)^{\mu-1}=A \mu$.

These equations lead to the second part of equations (11)-(13). 
Table 1. Structure of Export Receipts in Thailand (Percent share)

\begin{tabular}{|l|c|c|c|c|c|c|}
\hline \multicolumn{1}{|l|}{ Currencies } & \multicolumn{10}{|c|}{} \\
\hline US dollar & $\mathbf{1 9 9 3}$ & $\mathbf{1 9 9 4}$ & $\mathbf{1 9 9 5}$ & $\mathbf{1 9 9 6}$ & $\mathbf{1 9 9 7}$ & $\mathbf{1 9 9 8}$ \\
Baht & 91.8 & 90.5 & 91.0 & 91.7 & 92.0 & 90.6 \\
Japanese yen & 0.9 & 1.6 & 2.4 & 1.3 & 2.1 & 2.6 \\
Deutsche mark & 3.9 & 4.7 & 4.1 & 4.5 & 3.3 & 3.7 \\
Pound sterling & 1.0 & 0.8 & 0.5 & 0.5 & 0.4 & 0.7 \\
Euro & 0.8 & 0.6 & 0.3 & 0.4 & 0.3 & 0.4 \\
Singapore dollar & 0.0 & 0.0 & 0.0 & 0.0 & 0.0 & 0.0 \\
Others & 0.8 & 0.7 & 0.5 & 0.4 & 0.4 & 0.3 \\
\hline \multicolumn{1}{|c|}{ Total } & 0.8 & 1.1 & 1.2 & 1.2 & 1.5 & 1.7 \\
\hline
\end{tabular}

\begin{tabular}{|l|c|c|c|c|c|}
\hline \multicolumn{1}{|l|}{ Currencies } & \multicolumn{10}{|c|}{} \\
\cline { 1 - 5 } US dollar & 87.6 & 87.0 & 85.7 & 84.7 & 84.4 \\
Baht & 3.7 & 3.9 & 4.0 & 4.3 & 5.0 \\
Japanese yen & 5.2 & 5.7 & 5.6 & 6.0 & 5.9 \\
Deutsche mark & 1.5 & 1.2 & 0.8 & 0.0 & 0.0 \\
Pound sterling & 0.3 & 0.2 & 0.3 & 0.3 & 0.3 \\
Euro & 0.2 & 0.6 & 2.0 & 3.2 & 2.7 \\
Singapore dollar & 0.3 & 0.2 & 0.3 & 0.3 & 0.3 \\
Others & 1.2 & 1.2 & 1.3 & 1.2 & 1.4 \\
\hline \multicolumn{1}{|c|}{ Total } & $\mathbf{1 0 0 . 0}$ & $\mathbf{1 0 0 . 0}$ & $\mathbf{1 0 0 . 0}$ & $\mathbf{1 0 0 . 0}$ & $\mathbf{1 0 0 . 0}$ \\
\hline
\end{tabular}

Sources) The Bank of Thailand. 
Table 2. Structure of export receipts from major trading partners classified by currency in Thailand (Percent share)

\begin{tabular}{|c|c|c|c|c|c|c|}
\hline \multirow{2}{*}{ Partner Country } & \multicolumn{3}{|c|}{2001} & \multicolumn{3}{|c|}{2002} \\
\hline & USD & JPY & THB & USD & JPY & THB \\
\hline Japan & 71.8 & 20.5 & 7.3 & 71.0 & 20.9 & 7.4 \\
\hline NAF & USI & JPY & THB & USD & JPY & THB \\
\hline$-U$ & 97.1 & 0.3 & 2. & 96 & 0 . & 3.2 \\
\hline$-\mathrm{Ca}$ & 97 & 0.0 & 0.2 & 97 & 0.2 & $0 . \overline{3}$ \\
\hline - Mex & 99.7 & 0.0 & 0.2 & 98.1 & 0.0 & 0.2 \\
\hline Total & 97.1 & 0.3 & 2.5 & 96.4 & 0.4 & 3.0 \\
\hline
\end{tabular}

\begin{tabular}{|c|c|c|c|c|c|c|}
\hline \multirow{2}{*}{ Partner Country } & \multicolumn{6}{|c|}{2002} \\
\hline & USD & GBP & DEM & THB & EURO & Others \\
\hline European Union & & & & & & \\
\hline $\begin{array}{l}\text { - Belgium } \\
\text { - Denmark }\end{array}$ & $\begin{array}{l}74.5 \\
92.8\end{array}$ & $\begin{array}{l}2.0 \\
0.0\end{array}$ & $\begin{array}{l}0.0 \\
0.0\end{array}$ & $\begin{array}{l}1.8 \\
2.6\end{array}$ & 21.4 & 0.3 \\
\hline - France & 87.2 & 0.0 & 0.0 & 0.8 & 11.4 & 0.6 \\
\hline - Germany & 50.1 & 0.0 & 0.2 & 1.1 & 47.8 & 0.8 \\
\hline - Greece & 81.7 & 0.0 & 0.0 & 0.6 & 17.6 & 0.1 \\
\hline - Ireland & 96.6 & 0.0 & 0.1 & 0.0 & 2.2 & 1.1 \\
\hline - Italy & 83.4 & 0.0 & 0.0 & 0.5 & 15.4 & 0.7 \\
\hline - Luxembourg & 16.7 & 0.0 & 0.0 & 0.0 & 83.1 & 0.2 \\
\hline - Netherlands & 61.4 & 0.0 & 0.0 & 0.3 & 37.4 & 0.9 \\
\hline - Portugal & 74.1 & 0.0 & 0.7 & 0.2 & 24.9 & 0.1 \\
\hline - Spain & 81.4 & 0.2 & 0.1 & 0.4 & 17.7 & 0.2 \\
\hline - United Kingdom & 88.5 & 6.8 & 0.0 & 2.1 & 2.4 & 0.2 \\
\hline - Austria & 41.2 & 0.0 & 0.2 & 7.5 & 50.9 & 0.2 \\
\hline - Sweden & 88.7 & 0.1 & 0.0 & 4.3 & 1.2 & 5.7 \\
\hline - Finland & 91.2 & 0.0 & 0.0 & 0.8 & 6.5 & 1.5 \\
\hline Total & 73.0 & 2.1 & 0.1 & 1.3 & 22.9 & 0.6 \\
\hline
\end{tabular}

\begin{tabular}{|c|c|c|c|c|c|c|}
\hline \multirow{2}{*}{ Partner Country } & \multirow{2}{*}{\multicolumn{6}{|c|}{2002}} \\
\hline & USD & JPY & THB & & & \\
\hline ASEAN & & & & & & \\
\hline $\begin{array}{l}\text { - Singapore } \\
\text { - Indonesia }\end{array}$ & $\begin{array}{l}91.6 \\
79.2\end{array}$ & $\begin{array}{l}2.2 \\
2.8\end{array}$ & $\begin{array}{l}3.3 \\
10.3\end{array}$ & $\begin{array}{l}1.3 \\
0.2\end{array}$ & $\begin{array}{l}0.0 \\
0.0\end{array}$ & $\begin{array}{l}1.6 \\
7.5\end{array}$ \\
\hline - Philippines & 84.2 & 1.9 & 5.9 & 6.8 & 0.0 & 1.2 \\
\hline - Malaysia & 93.3 & 1.1 & 3.8 & 0.4 & 0.8 & 0.6 \\
\hline - Brunei Darussalam & 64.5 & 0.4 & 9.3 & 25.2 & 0.0 & 0.6 \\
\hline - Cambodia & 47.0 & 0.2 & 52.0 & 0.4 & 0.0 & 0.4 \\
\hline - Laos & 49.3 & 0.2 & 49.9 & 0.0 & 0.0 & 0.6 \\
\hline - Myanmar & 65.6 & 0.2 & 33.7 & 0.0 & 0.1 & 0.4 \\
\hline - Vietnam & 95.9 & $0 . \overline{5}$ & 3.5 & 0.0 & 0.0 & 0.1 \\
\hline Total & 89.0 & 1.9 & 6.1 & 1.3 & 0.1 & 1.6 \\
\hline
\end{tabular}

Sources) The Bank of Thailand.

Notes of Table 2) USD $=$ US dollar, JPY $=$ Japanese Yen, THB $=$ Thai Baht, GBP $=$ Pound Sterling, $\mathrm{SGD}=$ Singapore Dollar, $\mathrm{DEM}=$ Deutsche Mark, and MYR $=$ Malaysian Ringitt. 
Table 3. The Shares of Payment Currencies in Korean Exports

(1) Visible Trade

\begin{tabular}{|c|c|c|c|c|}
\hline & US Dollar & Yen & Mark & Pound \\
\hline 1976 & 99.08 & 0 & 0.25 & 0.37 \\
\hline 1980 & 95 & 2.15 & 1.58 & 0.45 \\
\hline 1985 & 94.24 & 3.84 & 0.76 & 0.38 \\
\hline 1990 & 88.21 & 7.44 & 2.2 & 0.87 \\
\hline 1992 & 88.78 & 6.25 & 2.82 & 0.85 \\
\hline 1994 & 88.86 & 6.41 & 2.58 & 0.50 \\
\hline 1996 & 89.1 & 5.13 & 2.21 & 0.98 \\
\hline 1997 & 89.21 & 5.02 & 1.76 & 0.85 \\
\hline 1998 & 88.54 & 4.95 & 2.66 & 0.97 \\
\hline 1999 & 85.61 & 5.96 & 2.39 & 0.95 \\
\hline 2000 & 84.76 & 5.39 & 1.8 & 0.67 \\
\hline 2001 & 87.42 & 5.39 & 1.47 & 0.71 \\
\hline
\end{tabular}

(2) Invisible Trade

\begin{tabular}{|r|r|r|r|r|}
\hline & US Dollar & Yen & Mark & Pound \\
\hline 1976 & 83.86 & 5.73 & 2.09 & 0.29 \\
1980 & 83.45 & 4.60 & 0.98 & 0.39 \\
1985 & 87.78 & 8.86 & 0.97 & 0.41 \\
1990 & 65.58 & 25.67 & 2.99 & 2.81 \\
1992 & 67.79 & 22.51 & 3.65 & 2.06 \\
1994 & 70.08 & 22.09 & 3.11 & 0.91 \\
1996 & 75.48 & 17.18 & 2.40 & 0.80 \\
1997 & 77.22 & 15.77 & 2.35 & 0.99 \\
1998 & 77.79 & 16.32 & 1.79 & 0.67 \\
1999 & 74.52 & 18.96 & 1.12 & 1.03 \\
2000 & 75.87 & 16.27 & 0.65 & 1.23 \\
2001 & 74.38 & 14.06 & 0.47 & 1.37 \\
\hline
\end{tabular}

Sources) The Bank of Korea, Monthly Statistical Bulletin, various issues. 
Table 4. Korea and Thailand's exporting destinations ( exports to an area / exports to the world)

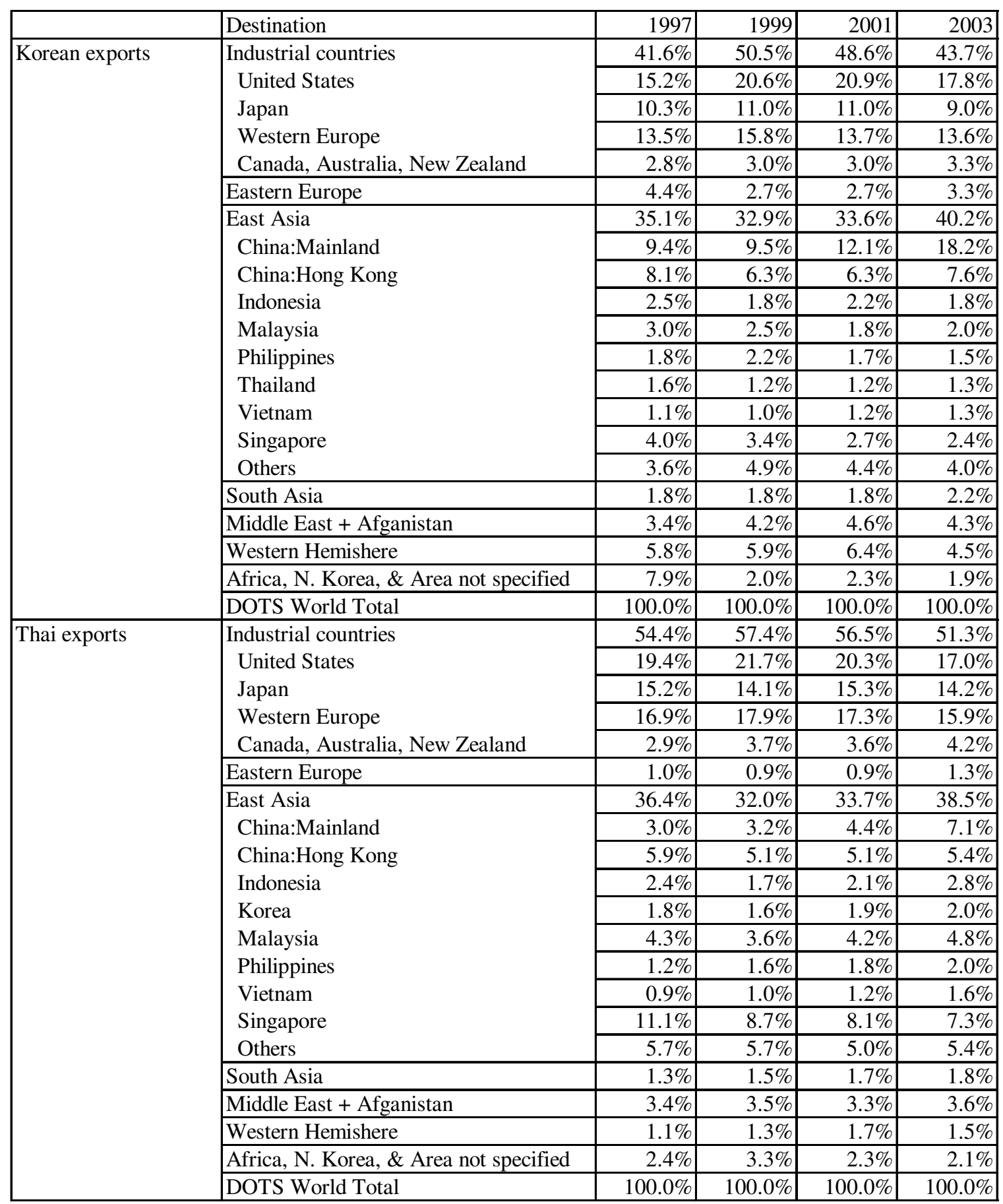

Source: IMF DOTS(Direction of trade statistics)

Note :South Asia includes Pakistan, Nepal, Indea, Sri Lanka, Bhutan, Bangladesh, and Maldives. 


\section{Table 5. Components of Export Receipts in Thailand}

\begin{tabular}{|l|c|c|}
\hline & \multicolumn{2}{|c|}{$($ P e r e e $\mathrm{t}$ s h a re $)$} \\
\hline FX reciepts exchanged to baht & $\mathbf{2 0 0 1}$ & $\mathbf{2 0 0 2}$ \\
Baht receipts through non-residents baht. & 63.9 & 66.8 \\
Payment to foreign creditors & 4.2 & 4.7 \\
Deposit to foreign currency A/C & 1.0 & 0.8 \\
\hline \multicolumn{1}{|c|}{ Total } & 30.9 & 27.7 \\
\hline
\end{tabular}

Sources) The Bank of Thailand. 
Table 6. The Discounted Utilities for Alternative Values of $\alpha$ and $\beta$

(1) $\alpha=1$

\begin{tabular}{|r|l|l|l|}
\hline$\beta$ & $V_{t}{ }^{0}$ & $V_{t}{ }^{E}$ & $V_{t}{ }^{I}$ \\
\hline 0.9 & 40.5077 & 40.5605 & 40.5352 \\
0.8 & 33.2652 & 33.2870 & 33.2769 \\
0.7125 & 28.1094 & 28.1111 & 28.1107 \\
0.71 & 27.9766 & 27.9778 & 27.9776 \\
0.7075 & 27.8445 & 27.8452 & 27.8453 \\
0.705 & 27.7131 & 27.7134 & 27.7137 \\
0.7025 & 27.5826 & 27.5823 & 27.5829 \\
0.7 & 27.4527 & 27.4520 & 27.4528 \\
0.6975 & 27.3236 & 27.3225 & 27.3235 \\
0.695 & 27.1953 & 27.1937 & 27.1949 \\
\hline
\end{tabular}

(2) $\alpha=0.9$

\begin{tabular}{|r|l|l|l|}
\hline$\beta$ & $V_{t}{ }^{0}$ & $V_{t}{ }^{E}$ & $V_{t}{ }^{I}$ \\
\hline 0.9 & 40.5303 & 40.5503 & 40.5410 \\
0.85 & 36.7111 & 36.7189 & 36.7155 \\
0.84 & 35.9950 & 36.0005 & 35.9983 \\
0.83 & 35.2943 & 35.2976 & 35.2964 \\
0.825 & 34.9496 & 34.9518 & 34.9512 \\
0.82 & 34.6086 & 34.6098 & 34.6097 \\
0.815 & 34.2713 & 34.2715 & 34.2719 \\
0.81 & 33.9377 & 33.9369 & 33.9377 \\
0.805 & 33.6077 & 33.6059 & 33.6072 \\
0.8 & 33.2813 & 33.2786 & 33.2804 \\
\hline
\end{tabular}


Table 6. The Discounted Utilities for Alternative Values of $\alpha$ and $\beta$ (continued)

(3) $\alpha=0.8$

\begin{tabular}{|r|r|r|r|}
\hline$\beta$ & $V_{t}{ }^{0}$ & $V_{t}^{E}$ & $V_{t}{ }^{I}$ \\
\hline 0.99 & 48.5199 & 48.5260 & 48.5234 \\
0.98 & 47.5603 & 47.5642 & 47.5628 \\
0.975 & 47.0878 & 47.0905 & 47.0896 \\
0.97 & 46.6200 & 46.6216 & 46.6213 \\
0.965 & 46.1569 & 46.1575 & 46.1576 \\
0.96 & 45.6985 & 45.6980 & 45.6987 \\
0.955 & 45.2448 & 45.2432 & 45.2444 \\
0.95 & 44.7957 & 44.7930 & 44.7948 \\
0.94 & 43.9111 & 43.9065 & 43.9092 \\
0.93 & 43.0446 & 43.0380 & 43.0417 \\
\hline
\end{tabular}

(4) $\alpha=0.75$

\begin{tabular}{|r|r|r|r|}
\hline$\beta$ & $V_{t}{ }^{0}$ & $V_{t}^{E}$ & $V_{t}^{I}$ \\
\hline 1 & 49.5114 & 49.4990 & 49.5056 \\
0.999 & 49.4126 & 49.4000 & 49.4066 \\
0.995 & 49.0193 & 49.0059 & 49.0130 \\
0.99 & 48.5321 & 48.5178 & 48.5253 \\
0.98 & 47.5722 & 47.5561 & 47.5645 \\
0.97 & 46.6315 & 46.6137 & 46.6229 \\
0.96 & 45.7097 & 45.6903 & 45.7003 \\
0.95 & 44.8065 & 44.7855 & 44.7963 \\
0.94 & 43.9216 & 43.8991 & 43.9106 \\
0.93 & 43.0547 & 43.0307 & 43.0430 \\
\hline
\end{tabular}

Note) Each shaded area denotes the largest utility for each $b$. 
Table 7. Invoice Currency Ratios in Japan's Exports

For Total World

\begin{tabular}{|l|rrrrrrrr|}
\hline & 1969 & 1970 & 1971 & 1972 & 1973 & 1974 & 1975 & 1976 \\
\hline Yen & 0.6 & 0.9 & 2.0 & 8.6 & 11.3 & 15.0 & 17.0 & 19.4 \\
US dollar & 90.1 & 90.5 & 90.4 & 82.8 & 81 & 77.7 & 78.5 & 76.3 \\
\hline
\end{tabular}

\begin{tabular}{|l|rrrrrrrr|}
\hline & 1977 & 1978 & 1980 & 1981 & 1982 & 1983 & 1984 & 1985 \\
\hline Yen & 18.8 & 19.8 & 28.9 & 31.8 & 33.8 & 40.5 & 39.5 & 39.3 \\
US dollar & 76.9 & 75.4 & 66.3 & 62.8 & 60.9 & 50.2 & 53.1 & 52.2 \\
\hline
\end{tabular}

\begin{tabular}{|l|cccccccc|}
\hline & 1986 & 1987 & 1988 & 1989 & 1990 & 1991 & 1992 & 1993 \\
\hline Yen & 35.5 & 33.4 & 34.3 & 34.7 & 37.5 & 39.4 & $40.1^{* * *}$ & $39.9^{* * *}$ \\
US dollar & 53.5 & 55.2 & 53.2 & 52.4 & 48.8 & 46.7 & $46.6^{* *}$ & $48.6^{* *}$ \\
\hline & & 3 & & & & & & \\
\hline & 1994 & 1995 & 1996 & 1997 & 1998 & 2000 & 2001 & 2002 \\
\hline Yen & 39.7 & 36.0 & 35.2 & 35.8 & 36.0 & $36.1^{\# \#}$ & $35.6^{\# \#}$ & $36.7^{\# \#}$ \\
\hline US dollar & & & & & - & - & - & - \\
\hline
\end{tabular}

For East Asia

\begin{tabular}{|l|rrrrrrrr|}
\hline & 1981 & 1983 & 1985 & 1987 & 1988 & 1989 & 1990 & 1991 \\
\hline Yen & 29.8 & 48 & 47.3 & 41.1 & 41.2 & 43.5 & 48.9 & 50.8 \\
US dollar & 68.9 & - & 51.3 & 56.5 & 56 & 53.6 & 48.1 & 45.9 \\
\hline
\end{tabular}

\begin{tabular}{|l|cccccccc|}
\hline & 1992 & 1993 & 1994 & 1995 & 1996 & 1997 & 2000 & 2002 \\
\hline Yen & 52.3 & 52.5 & 49.0 & 44.3 & 46.3 & 47.0 & $50.0^{\text {\#\# }}$ & $51.3^{\text {\#\# }}$ \\
US dollar & - & - & - & - & - & - & - & - \\
\hline
\end{tabular}

NOTES 1) Unless specified, the data are averaged annually.

2) The data with $*$ show figures for fiscal year.

3) The data with ** show those of September.

4) The data with \#\# show those of the second half ot the year.

SOURCES 1) Exports: Until 1982, Yushutsu Shinyojyo Toukei by Bank of Japan; between 1983 and 1991,

Export Confirmation Statistics by MITI. For 1992, Kessai Tuka Douko by MITI.

2) Imports: Until 1980, Yushutsu Syonin Todokede Houkokusho by MITI; Between 1981 and 1985,

Houkokusyorei Ni Motoduku Houkoku by Ministry of Finace; Between 1986 and 1991, Import

Reporting Statistics by MITI.

For 1992, Kessai Tuka Douko by MITI. For 1993, Yusyutu (Yunyu) Houkokusyo Douko by MITI. 

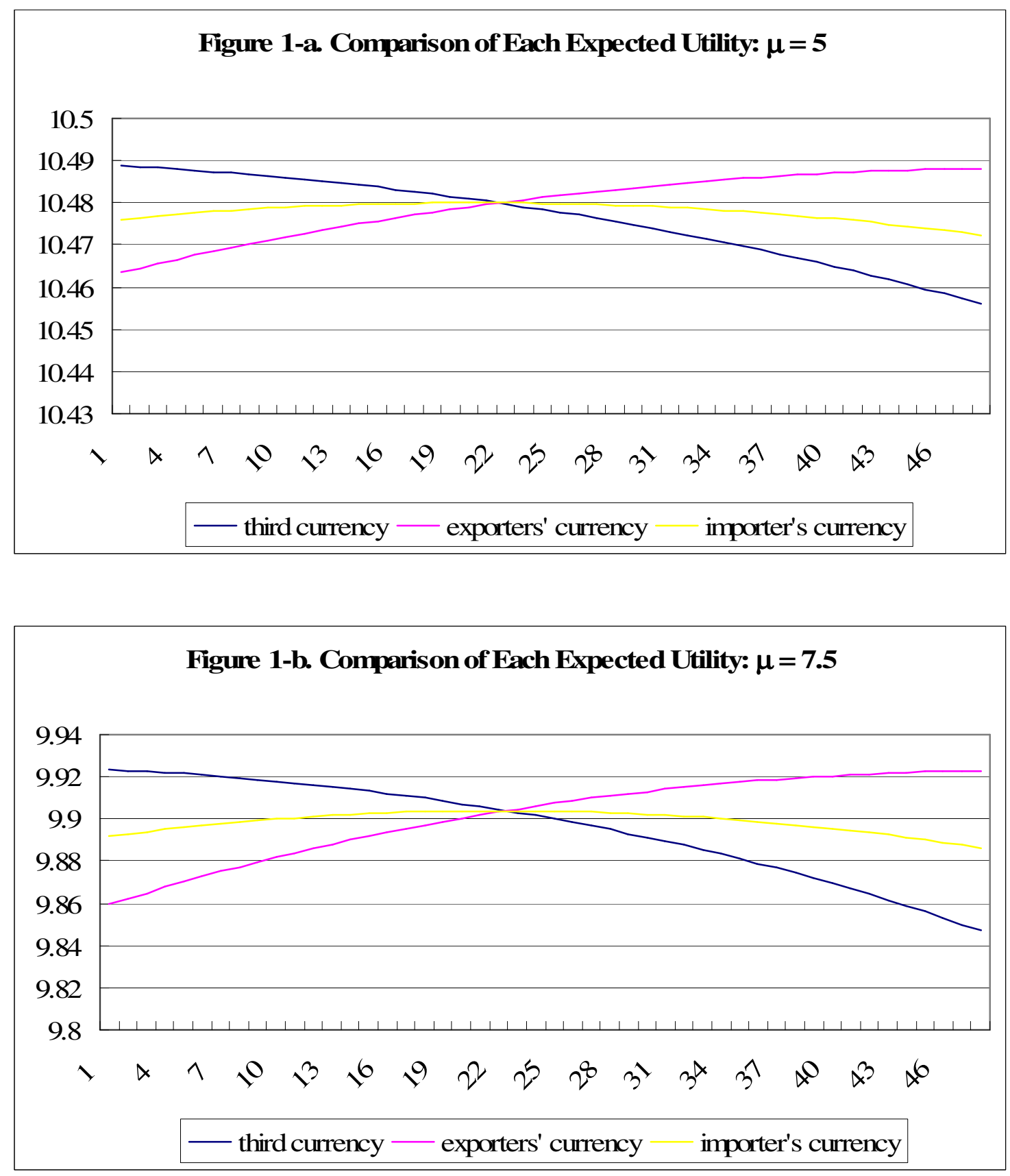


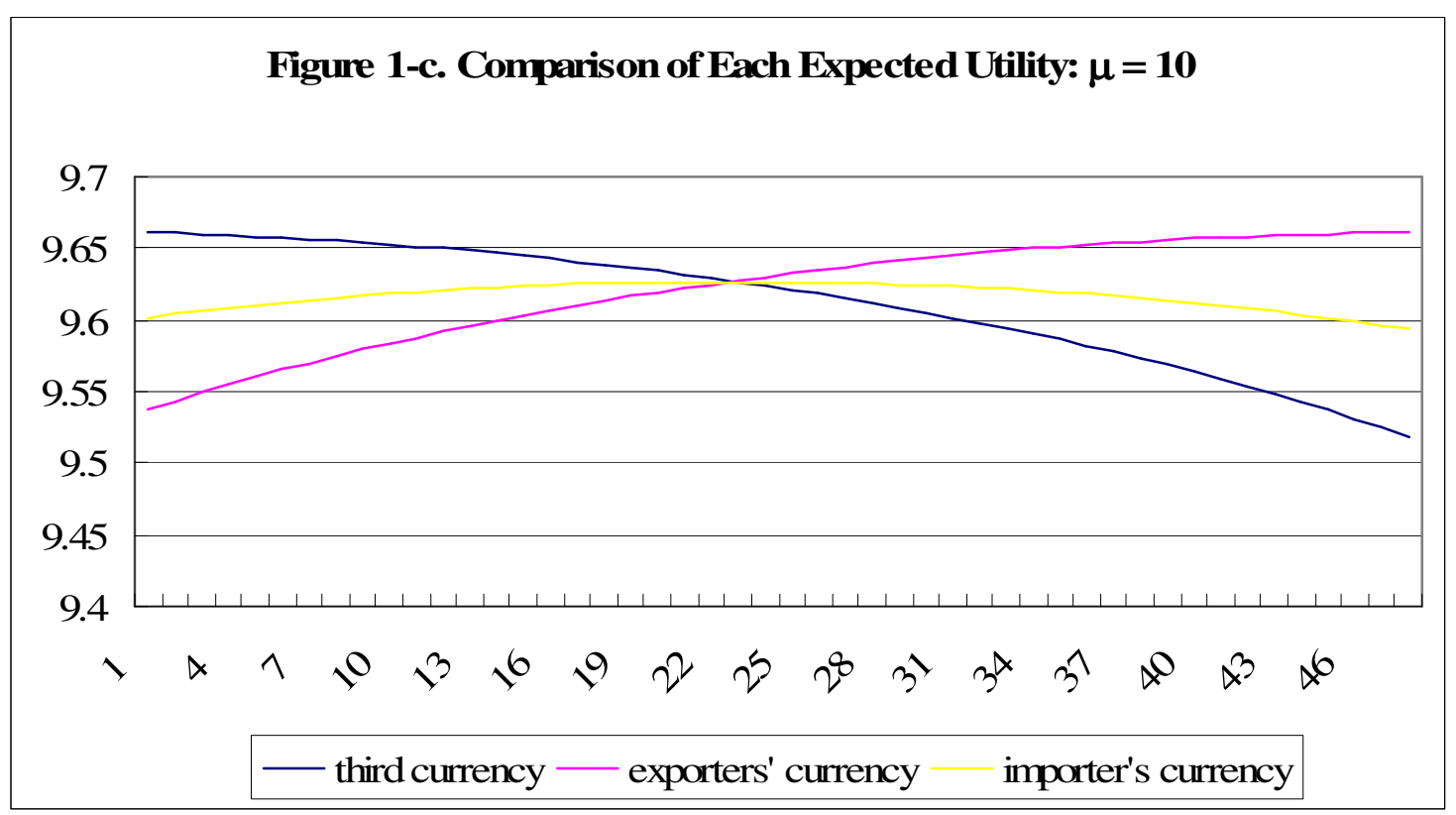

